\title{
PEMODELAN WAKTU TUNGGU PENUMPANG PADA JALUR ANGKUTAN DALAM KOTA PALU MENGGUNAKAN ALJABAR MAX-PLUS
}

\author{
Y. Natalia' ${ }^{1}$ I W. Sudarsana ${ }^{2}$, dan D. Lusiyanti ${ }^{3}$ \\ 1,2,3 Program Studi Matematika Jurusan Matematika \\ Fakultas Matematika dan IImu Pengetahuan Alam Universitas Tadulako \\ Jalan Soekarno-Hatta Km. 09 Tondo, Palu 94118, Indonesia. \\ 1yeri.natalia@yahoo.com, ${ }^{2}$ sudarsanaiwayan@yahoo.co.id, ${ }^{3}$ desilusiyanti@yahoo..com
}

\begin{abstract}
Passenger waiting time is the time required by passengers starting from the stops until getting transport. The purpose of this research is to get the model of waiting time passengers on the freight line in the Palu city. The first step is the preparation of directed graphs based on the existring routes, then calculate the mileage and travel time using synchronization rules and power algorithm with initial vector $x=0$ obtained the value $p=2, q=1$ and $c=$ 102 by using the appplication rock Scilab 5.5.2 and Map-Plus Toolbox obtained eigenvalues as the departure period of 102 and eigenvektor as the initial departure time.
\end{abstract}

Keywords : Eigenvalues, Eigenvectors, Max-Plus Algebra, Waiting Time.

\section{ABSTRAK}

Waktu tunggu penumpang adalah waktu yang diperlukan oleh penumpang mulai dari tempat pemberhentian sampai dengan memperoleh angkutan. Tujuan dari penelitian ini adalah untuk mendapatkan model waktu tunggu penumpang pada jalur angkutan di kota Palu. Langkah pertama yang dilakukan yaitu penyusunan graf berarah berdasarkan rute yang sudah ada, selanjutnya mengitung jarak tempuh dan waktu tempuh menggunakan aturan sinkronisasi dan algoritma power dengan vektor awal $x=0$ diperoleh nilai $p=2, q=1$ dan $c=102$. Dengan bantuan aplikasi Scilab 5.5.2 dan Max-Plus Toolbox diperoleh nilai eigen yaitu 102. Sedangkan nilai vector eigen digunakan sebagai waktu keberangkatan awal.

Kata kunci : Nilai Eigen, Vektor Eigen,Aljabar Max-Plus, Waktu Tunggu. 


\section{PENDAHULUAN}

\subsection{Latar Belakang}

Transportasi adalah pemindahan manusia atau barang dari satu tempat ketempat lainnya dengan menggunakan sebuah wahana yang digerakkan oleh manusia atau mesin. Transportasi sangat penting untuk manusia, karena memudahkan manusia dalam melakukan aktivitas sehari-hari. Ada bermacam-macam sarana transprotasi yang umum digunakan seperti mobil, motor, bus, angkutan kota dan sebagainya (Rianty, 2015).

Angkutan merupakan sarana untuk memindahkan orang atau barang dari suatu tempat ketempat lain. Keberadaan angkutan umum di suatu wilayah atau kota diharapkan dapat mendukung aktivitas masyarakat dalam pemenuhan kebutuhannya. Namum masalah yang sering terjadi pada angkutan umum adalah masalah waktu tunggu. Terkadang masyarakat harus menunggu cukup lama untuk mendapatkan angkutan yang akan membawahnya ketempat tujuan (Ira dkk, 2010).

Masalah ini berkaitan dengan teori penjadwalan dan dapat diselesaikan dengan memanfaatkan metode Aljabar Maxplus seperti penelitian yang dikerjakan oleh Ayu (2013) tentang Kajian Aljabar Max-Plus pada Pemodelan dan Penjadwalan Monorel dan Trem yang Terintegrasi di Kota Surabaya. Pada tahun yang sama oleh Oktafianto (2013) Aljabar Max-Plus digunakan untuk Implementasi pada Pemolandan Penjadwalan Keberangkatan Bus Kota DAMRI (Studi Kasus di Surabaya). Kemudian pada tahun 2014 oleh Rakhmawatii melakukan penelitian tentang studi Penerapan Bus Sekolah di Jombang menggunakan Aljabar Max-Plus. Dan pada tahun 2015 oleh Hasanah dan Putrawangsa menggunakan Aljabar Max-Plus dalam Pembentukan Model Matematis pada Sistem Penjadwalan Praktikum Laboratorium.

Permasalahan yang terjadi pada angkutan umum di kota Palu adalah berkurangangnya angkutan yang beroperasi akibatnya terjadi waktu tunggu untuk mendapatkan angkutan, karena banyak masyarakat memilih menggunakan kendaraan pribadi, pengaturan jadwal yang kurang tepat dan penentuan rute perjalanan yang belum maksimal, sehingga mengakibatkan berkurangnya minat penumpang untuk memanfaatkan fasilitas angkutan umum. Hal inilah yang membuat penulis mencoba membuat model waktu tunggu penumpang dengan menggunakan metode Aljabar Max-Plus.

\subsection{Batasan Masalah}

Penelitian ini dibatasi oleh Studi kasus yang digunakan berbasis jalan yang sudah ada di Kota Palu, denganrute Terminal Mamboro ke Terminal Tipo yang dibuat pada skripsi Nurhayati (2015) yang berjudul Pembuatan Skema Jalur Angkutan Kota Palu Berdasarkan Pencarian Lintasan dengan Bobot Maksimum menggunakan Algoritma Ant Colony System (ACS). 


\section{TINJAUAN PUSTAKA}

\subsection{Aljabar Max-Plus}

Aljabar max-plus digunakan untuk menganalisa kemungkinan realisasi dari jalur yang dirancang dengan melihat kestabilan dari sistem yang dibentuk berdasarkan jalur yang dirancang.

Definisi 1 (Subiono, 2012) :

Diberikan $\mathbb{R}_{\varepsilon} \stackrel{\text { def }}{=} \mathbb{R} \cup\{\varepsilon\}$ dengan $\mathbb{R}$ adalah himpunan semua bilangan real dan $\varepsilon \stackrel{\text { def }}{=}-\infty$. Pada $\mathbb{R}_{\varepsilon}$ didefinisikan operasi berikut : $\forall x, y \in \mathbb{R}_{\varepsilon}$,

$$
x \oplus y \stackrel{\text { def }}{=} \max \{x, y\} \text { dan } x \otimes y \stackrel{\text { def }}{=} x+y .
$$

Untuk selanjutnya operasi $\oplus$ dibaca o-plus dan operasi $\otimes$ dibaca o-times dan juga penulisan $\left(\mathbb{R}_{\varepsilon}, \otimes, \oplus\right)$ ditulis sebagai $\mathbb{R}_{\text {max }}$. Selanjutnya ditunjukkan $\left(\mathbb{R}_{\varepsilon}, \otimes, \oplus\right)$ merupakan semiring dengan elemen netral $\varepsilon$ dan elemen satuan $e=0$, karena untuk setiap $x, y, z \in \mathbb{R}_{\varepsilon}$ berlaku :

a) $\quad x \oplus y=\max \{x, y\}=\max \{y, x\}=y \oplus x$,

$(x \oplus y) \oplus z=\max \{\max \{\ddot{e}, y\}, z\}=\max \{x, y, z\}=\max \{x, \max \{y, z\}\}=x \oplus(y \oplus z)$,

$x \oplus \varepsilon=\max \{x,-\infty\}=\max \{-\infty, x\}=\varepsilon \oplus x=x$.

b) $(x \otimes y) \otimes z=(x+y)+z=x+(y+z)=x \otimes(y \otimes z)$,

$x \otimes e=x+0=0+x=e \otimes x=x$,

c) $\quad x \otimes \varepsilon=x+(-\infty)=-\infty=-\infty+x=\varepsilon \otimes x$

d) $\quad(x \oplus y) \otimes z=\max \{x, y\}+z=\max \{x+z, \square+z\}=(x \otimes z)(y \otimes z)$,

$x \otimes(y \oplus z)=x+\max \{y, z\}=\max \{x+y, x+z\}=(x \otimes y) \oplus(x \otimes z)$.

\subsection{Vektor dan Matriks}

Himpunan matriks ukuran $n \times m$ dalam aljabar max-plus dinotasikan oleh $\mathbb{R}_{\varepsilon}^{n \times m}$. Didefinisikan $n=\{1,2,3, \ldots, n\}$ untuk $n \in N$. Elemen dari matriks $A \in \mathbb{R}_{\max }^{n \times n}$ pada baris ke- $i$ kolom ke-j dinyatakan dengan $a_{i, j}$, untuk $i \in n$ dan $j \in m$. Dalam hal ini matriks $A$ dapat dituliskan sebagai:

$$
A=\left[\begin{array}{cccc}
a_{1,1} & a_{1,2} & \ldots & \ldots \\
a_{1, m} \\
a_{2,1} & a_{2,2} & \ldots & a_{2, m} \\
\vdots & \vdots & \ddots & \vdots \\
a_{n, 1} & a_{n, 2} & \ldots & a_{n, m}
\end{array}\right]
$$

ada kalanya elemen $a_{i, j}$ juga dinotasikan sebagai $[A]_{i, j} i \in n, j \in m$.

Untuk penjumlahan matriks $A, B \in \mathbb{R}_{\max }^{n \times m}$ dinotasikan oleh $A \oplus B$ didefinisikan sebagai

untuk $i \in n$ dan $j \in \mathrm{m}$.

$$
\begin{aligned}
{[A \oplus B]_{i, j} } & =a_{i, j} \oplus b_{i, j} \\
& =\max \left\{a_{i, j}, b_{i, j}\right\}
\end{aligned}
$$

\subsection{Matriks dan Graf}


Misalkan matriks $A \in \mathbb{R}_{\max }^{n \times n}$ dan suatu graf berarah dari matriks tersebut adalah $G(A)=$ $(E, V)$. Graph $G(A)$ memiliki $n$ titik dan semua himpunan titik dari $G(A)$ dinyatakan oleh $V$. Suatu garis dari titik $j$ ke titik $i$ ada bila $a_{i, j} \neq \varepsilon \cdot$, garis ini dinotasikan oleh $(j, i)$. Himpunan semua garis dari graf $G(A)$ dinotasikan oleh $E$. Bobot dari garis $(j, i)$ adalah nilai dari $a_{i, j}$ yang dinotasikan oleh $w(j, i)=a_{i, j} \in \mathbb{R}$. Bila $a_{i, j}=\varepsilon$, maka garis $(j, i)$ tidak ada.Suatu barisan garis $\left(i_{1}, i_{2}\right),\left(i_{2}, i_{3}\right), \ldots,\left(i_{1-1}, i_{1}\right)$ dari suatu graf dinamakan suatu path. Suatu path dikatakan elementer bila tidak ada titik terjadi dua kali dalam path tersebut. Untuk suatu matriks persegi, $A \in \mathbb{R}_{\max }^{n \times n}$, matriks $A^{\mathrm{T}}$ didefinisikan sebagai:

$$
A^{+} \stackrel{\text { def }}{=} \bigoplus_{i=1}^{\infty}, A^{\otimes 1}
$$

\subsection{Nilai Eigen dan Vektor Eigen}

Pengertian dari nilai eigen dan vektor eigen yang bersesuaian dari suatu matriks persegi berukuran $n \times n$ dalam aljabar linear juga dijumpai dalam Aljabar Maxplus, yaitu bila diberikan suatu persamaan:

$$
A \otimes x=\lambda \otimes x
$$

Dalam hal ini masing-masing vektor $x \in \mathbb{R}_{\max }^{n \times n}$ dan $\lambda \in \mathbb{R}$ dinamakan vektor eigen dan nilai eigen dari matriks dengan vektor $\neq(\varepsilon, \varepsilon, \ldots, \varepsilon)^{\prime}$. Suatu algoritma untuk menentukan nilai eigen dan vektor eigen dari matriks $A \in \mathbb{R}_{\max }^{n \times n}$ dilakukan secara berulang dari bentuk persamaan linear

$$
x(k+1)=A \otimes x(k),=0,1,2,3, \ldots
$$

Perilaku periodik dari persamaan (1) erat kaitannya dengan apa yang dinamakan vektor waktu sikel yang didefinisikan sebagai:

$$
\lim _{k \rightarrow \infty} \frac{x(k)}{k} .
$$

Limit ini ada untuk setiap keadaan awal $x(0) \neq(\varepsilon, \varepsilon, \cdots, \varepsilon)^{\mathrm{T}}$ untuk matriks dalam Persamaan (1) yang tereduksi selalu bisa dijadikan suatu bentuk blok matriks segitiga atas, yang diberikan oleh bentuk

$$
\left[\begin{array}{cccc}
A_{1,1} & A_{1,2} & \ldots & A_{1, q} \\
\varepsilon & A_{2,2} & \ldots & A_{2, q} \\
\varepsilon & \varepsilon & \ddots & \vdots \\
\varepsilon & \varepsilon & \cdots & A_{q, q}
\end{array}\right]
$$

dan untuk setiap $i=1,2,3, \ldots, q, A_{i, i}$ berukuran $q_{i} \times q_{i}$ adalah matriks tak tereduksi dengan nilai eigen $\lambda_{i}$. Dalam hal yang demikian vektor waktu sikel diberikan oleh:

$$
\lim _{k \rightarrow \infty} \frac{x(k)}{k}=\left(\lambda_{1}^{\mathrm{T}} \lambda_{2}^{\mathrm{T}} \cdots \lambda_{q}^{\mathrm{T}}\right)^{\mathrm{T}}
$$

dengan tanda ${ }^{\mathrm{T}}$ menyatakan transpose dari matriks dan $\lambda_{i}=\left(\lambda_{i} \lambda_{i} \cdots \lambda_{i}\right)^{\mathrm{T}}$ dan vektor $\lambda_{i}$ berukuran $q_{i} \times 1$. Keadaan nilai eigen dari matriks persegi A diberikan dalam teorema berikut ini: 
Teorema 1 (Subiono, 2015) :

Bila untuk sebarang keadaan awal $x(0) \neq \varepsilon$ sistem persamaan (1) memenuhi $x(p)=c \otimes x(q)$ untuk beberapa bilangan bulat $p$ dan $q$ dengan $p>q \geq 0$ dan beberapa bilangan real $c$, maka

$$
\lim _{k \rightarrow \infty} \frac{x(k)}{k}=(\lambda \lambda \cdots \lambda)^{\mathrm{T}}
$$

dengan $\lambda=\frac{c}{p-q}$. Selanjutnya $\lambda$ adalah suatu nilai eigen dari matriks $A$ dengan vektor eigen diberikan oleh

$$
v=\oplus_{i-1}^{p-q}\left(\lambda^{\otimes(p-q-i)}\right) \otimes x(q+i-1)
$$

Berdasarkan teorema 1 dapat ditemukan nilai eigen sekaligus vector eigen dari suatu matriks persegi yang dikenal dengan algoritma power sebagai berikut :

1. Mulai dari sebarang vector awal $(0) \neq \varepsilon$

2. Iterasikan persamaan $x(k+1)=A \otimes x(k)$ sampai ada bilangan bulat $p>q \geq 0$ dan bilangan real $c$ yang memenuhi $x(p)=\mathrm{c} \otimes \mathrm{x}(\mathrm{q})$.

3. Hitung nilai eigen $\lambda=\frac{c}{p-q}$

4. Hitung vector eigen $v=\bigoplus_{i-1}^{p-q}\left(\lambda^{\otimes(p-q-i)}\right) \otimes x(q+i-1)$

Algoritma tersebut sudah diimplementasikan dengan Scilab dalam Max Plus Toolbax.

\section{METODE PENELITIAN}

Adapun prosedur yang dilakukan pada penelitian ini adalah sebagai berikut :

1. Melakukan studi literatur dengan mengumpulkan materi dan dari buku-buku, artikel, dan jurnal yang di dapatkan dari internet.

2. Mengumpulkan data jarak dan waktu tempuh dari jalur yang sudah ada pada skripsi Nurhayati.

3. Penyusunan graf.

4. Analisi pemodelan waktu tunggu penumpang menggunakan Aljabar Max-Plus

5. Menyimpulkan.

6. Selesai.

\section{HASIL DAN PEMBAHASAN}

\subsection{Jalur Angkutan di Kota Palu}

Jalur yang digunakan yaitu jalur Terminal Mamboro ke Terminal Tipo yang terbagi lagii menjadi 5 rute, jalur yang digunakan yaitu:

Jl. Trans Sulawesi $\left(T S_{1}\right) \rightarrow$ Jl. Yos Sudarso $\left(T S_{2}\right) \rightarrow$ Jl. Samratulangi $\left(T S_{3}\right) \rightarrow$ JI. S. Parman $\left(T S_{4}\right) \rightarrow \mathrm{J}$. Ki Hajar Dewantara $\left(T S_{5}\right) \rightarrow \mathrm{Jl}$. Sisinga Mangaraja $\left(T S_{6}\right) \rightarrow \mathrm{J}$. Moh. Yamin $\left(T S_{7}\right) \rightarrow$ Jl. Basuki Rahmat $\left(T S_{8}\right) \rightarrow$ Jl. I Gst Ngurah Rai $\left(T S_{9}\right) \rightarrow$ Jl. Lele Mina $\left(T S_{10}\right) \rightarrow$ Jl. Kramat Jaya $\left(T S_{11}\right) \rightarrow$ Jl. Tavanjuka Mas $\left(T S_{12}\right) \rightarrow$ Jl. Palupi Jaya $\left(T S_{13}\right) \rightarrow$ Jl. Poros Palupi $\left(T S S_{14}\right) \rightarrow$ Jl. Puebongo $\left(T S_{15}\right) \rightarrow$ Jl. I Gst Ngurah Rai $\left(T S_{16}\right) \rightarrow$ Jl. Padan Jakaya $\left(T S_{17}\right) \rightarrow$ Jl. G. Gawalise $\left(T S_{18}\right) \rightarrow$ Jl. Munif Rahmat $\left(T S_{19}\right) \rightarrow \mathrm{Jl}$. Malonda $\left(T S_{20}\right) \rightarrow \mathrm{Jl}$. Munif Rahmat $\left(T S_{19}\right) \rightarrow \mathrm{Jl}$. G. Gawalise $\left(T S_{18}\right) \rightarrow$ Jl. Padan Jakaya $\left(T S_{17}\right) \rightarrow$ Jl. I Gst Ngurah Rai $\left(T S_{16}\right) \rightarrow$ Jl. Puebongo 
$\left(T S_{15}\right) \rightarrow$ Jl. Poros Palupi $\left(T S_{14}\right) \rightarrow$ Jl. Palupi Jaya $\left(T S_{13}\right) \rightarrow$ Jl. Tavanjuka Mas $\left(T S_{12}\right) \rightarrow$ Jl. Kramat Jaya $\left(T S_{11}\right) \rightarrow$ Jl. Lele Mina $\left(T S_{10}\right) \rightarrow$ Jl. I Gst Ngurah Rai $\left(T S_{9}\right) \rightarrow$ Jl. Basuki Rahmat $\left(T S_{8}\right) \rightarrow$ Jl. Moh. Yamin $\left(T S_{7}\right) \rightarrow$ Jl. Sisinga Mangaraja $\left(T S_{6}\right) \rightarrow$ Jl. Ki Hajar Dewantara $\left(\right.$ 年 $\left._{5}\right)$ $\rightarrow$ Jl. S. Parman $\left(T S_{4}\right) \rightarrow$ Jl. Samratulangi $\left(T S_{3}\right) \rightarrow$ Jl. Yos Sudarso $\left(T S_{2}\right) \rightarrow$ Jl. Trans Sulawesi $\left(T S_{1}\right)$.

Dari jalur angkutan tersebut terdapat 19 titik pertemuan yang menghubungkan terminal Mamboro ke terminal Tipo.

\subsection{Penyusunan Graf Berarah}

Dalam penyusunan graf berarah diperlukan data-data berupa vertex yang dapat diartikan sebagai titik-titik pemberangkatan dan pemberhentian (angkutan kota) dan waktu tempuh. Dari data yang diperoleh dapat digambarkan graf berarah dimana vertex-vertexnya merupakan tempat pemberhentian sedangkan garis (edge) yang menghubungkan vertexvertex tersebut dinamakan path dengan bobot pada setiap edge adalah waktu tempuh ratarata antar penumpang $t_{i}$, untuk $i=1,2,3, \ldots, 38$. Arah graf didapatkan dari arah angkutan yang beroperasi sebagaimana telah di uraikan pada jalur Terminal Mamboro ke Terminal Tipo di kota Palu. Dalam pembahasan ini didapatkan graf berarah dari JI. Trans Sulawesi $\left(T S_{1}\right)$ menuju JI. Yos Sudarso $\left(T S_{2}\right)$ dengan waktu tempuh-tempuh rata-rata $t_{1}$. 


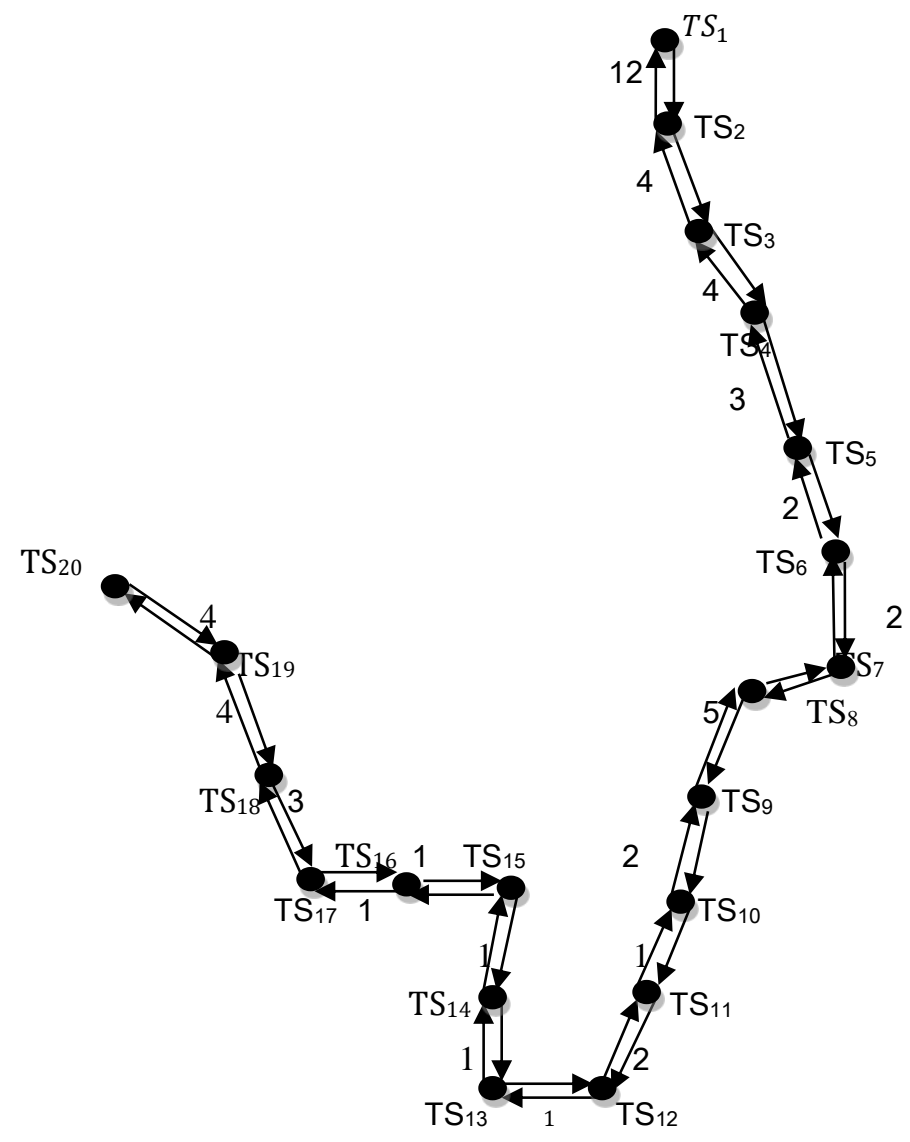

Gambar 1 : Graf berarah

\subsection{Sinkronisasi dan Penyusunan Model}

Sinkronisasi menjelaskan mengenai aturan keberangkatan angkutan dari suatu terminal yang harus menunggu kedatangan angkutan yang menuju ke terminal tersebut. Hal ini dimaksudkan untuk menjamin penumpang dapat berpindah dari suatu tempat ke tempat lainnya dengan jalur yang sama. Misalnya sebagai berikut :

- Keberangkatan angkutan ke- $(k+1)$ dari $T S_{2}$ menuju $T S_{3}$ menunggu ke datangan angkutan yang ke- $k$ dari $T S_{1}$ menuju $T S_{2}$

Pada Tabel 1 dapat dilihat pendefinisian variable waktu keberangkatan pada saat ke $\mathrm{k}$ sebagai berikut:

Tabel 1 : Pendefinian variable waktu keberangkatan pada saat ke $\mathrm{k}$

\begin{tabular}{|c|c|c|c|c|c|c|c|}
\hline Variabel & Dari & $\mathrm{Ke}$ & $\begin{array}{c}\text { Label waktu } \\
\text { tempuh } \\
\text { rata-rata }\end{array}$ & Variabel & Dari & $\mathrm{Ke}$ & $\begin{array}{c}\text { Label waktu } \\
\text { tempuh } \\
\text { rata-rata }\end{array}$ \\
\hline$x_{1}(k)$ & $T S_{1}$ & $T S_{2}$ & $t_{1}$ & $x_{20}(k)$ & $T S_{20}$ & $T S_{19}$ & $t_{20}$ \\
\hline$x_{2}(k)$ & $T S_{2}$ & $T S_{3}$ & $t_{2}$ & $x_{21}(k)$ & $T S_{19}$ & $T S_{18}$ & $t_{21}$ \\
\hline
\end{tabular}




\begin{tabular}{|c|c|c|c|c|c|c|c|}
\hline$x_{3}(k)$ & $T S_{3}$ & $T S_{4}$ & $t_{3}$ & $x_{22}(k)$ & $T S_{18}$ & $T S_{17}$ & $t_{22}$ \\
\hline$x_{4}(k)$ & $T S_{4}$ & $T S_{5}$ & $t_{4}$ & $x_{23}(k)$ & $T S_{17}$ & $T S_{16}$ & $t_{23}$ \\
\hline$x_{5}(k)$ & $T S_{5}$ & $T S_{6}$ & $t_{5}$ & $x_{24}(k)$ & $T S_{16}$ & $T S_{15}$ & $t_{24}$ \\
\hline$x_{6}(k)$ & $T S_{6}$ & $T S_{7}$ & $t_{6}$ & $x_{25}(k)$ & $T S_{15}$ & $T S_{14}$ & $t_{25}$ \\
\hline$x_{7}(k)$ & $T S_{7}$ & $T S_{8}$ & $t_{7}$ & $x_{26}(k)$ & $T S_{14}$ & $T S_{13}$ & $t_{26}$ \\
\hline$x_{8}(k)$ & $T S_{8}$ & $T S_{9}$ & $t_{8}$ & $x_{27}(k)$ & $T S_{13}$ & $T S_{12}$ & $t_{27}$ \\
\hline$x_{9}(k)$ & $T S_{9}$ & $T S_{10}$ & $t_{9}$ & $x_{28}(k)$ & $T S_{12}$ & $T S_{11}$ & $t_{28}$ \\
\hline$x_{10}(k)$ & $T S_{10}$ & $T S_{11}$ & $t_{10}$ & $x_{29}(k)$ & $T S_{11}$ & $T S_{10}$ & $t_{29}$ \\
\hline$x_{11}(k)$ & $T S_{11}$ & $T S_{12}$ & $t_{11}$ & $x_{30}(k)$ & $T S_{10}$ & $T S_{9}$ & $t_{30}$ \\
\hline$x_{12}(k)$ & $T S_{12}$ & $T S_{13}$ & $t_{12}$ & $x_{31}(k)$ & $T S_{9}$ & $T S_{8}$ & $t_{31}$ \\
\hline$x_{13}(k)$ & $T S_{13}$ & $T S_{14}$ & $t_{13}$ & $x_{32}(k)$ & $T S_{8}$ & $T S_{7}$ & $t_{32}$ \\
\hline$x_{14}(k)$ & $T S_{14}$ & $T S_{15}$ & $t_{14}$ & $x_{33}(k)$ & $T S_{7}$ & $T S_{6}$ & $t_{33}$ \\
\hline$x_{15}(k)$ & $T S_{15}$ & $T S_{16}$ & $t_{15}$ & $x_{34}(k)$ & $T S_{6}$ & $T S_{5}$ & $t_{34}$ \\
\hline$x_{16}(k)$ & $T S_{16}$ & $T S_{17}$ & $t_{16}$ & $x_{35}(k)$ & $T S_{5}$ & $T S_{4}$ & $t_{35}$ \\
\hline$x_{17}(k)$ & $T S_{17}$ & $T S_{18}$ & $t_{17}$ & $x_{36}(k)$ & $T S_{4}$ & $T S_{3}$ & $t_{36}$ \\
\hline$x_{18}(k)$ & $T S_{18}$ & $T S_{19}$ & $t_{18}$ & $x_{37}(k)$ & $T S_{3}$ & $T S_{2}$ & $t_{37}$ \\
\hline$x_{19}(k)$ & $T S_{19}$ & $T S_{20}$ & $t_{19}$ & $x_{38}(k)$ & $T S_{2}$ & $T S_{1}$ & $t_{38}$ \\
\hline
\end{tabular}

Berdasarkan data jalan dan aturan sinkronisasi, maka dapat dikonstrusikan model aljabar max-plus dari table 1 didapatkan persamaan sebagai berikut:

$$
x(k+1)={ }_{p=1} \oplus^{M}\left(A_{p} \otimes x(k+1-p)\right)
$$

dengan $A_{p}$ adalah matriks $n \times n$ dan $n$ adalah jumlah variabel. Matriks $A_{p}$ adalah matriks yang berkaitan dengan $x(k+1-p)$ dan $M$ merupakan jumlah angkutan maksimum diantara semua jalur.

Berdasarkan Tabel 1 jumlah variabel adalah 38 variabel dan jumlah angkutan maksimum dimisalkan 1 angkutan pada semua jalur, maka $n=38$ dan $M=1$. Sehingga matriks $A$ berukuran $38 \times 38$. Dengan algoritma power dan bantuan aplikasi Scilab diperoleh nilai $p=2, q=1$ dan $c=102$, dimana vektor awal $x=0$ sehingga nilai $\lambda=102$. Nilai eigen digunakan sebagai periode keberangkatan yaitu $\lambda=102$ atau 1 jam 42 menit dan vektor eigen sebagai waktu keberangkatan.

\section{KESIMPULAN}

1. Aljabar max-plus dapat diterapkan yang disusun menggunakan aljabar max-plus ini menghasilkan bentuk model $x(k+1)=A \otimes x(k)$.

2. Dari model yang didapatkan dan menggunakan bantuan aplikasi Scilab 5.5 .2 diperoleh nilai eigen sebagai periode keberangkatan adalah setiap 102 menit atau 1 jam 42 menit sekali. Sedangkan vektor eigen digunakan sebagai waktu keberangkatan. 


\section{DAFTAR PUSTAKA}

[1] Ayu, F, Kajian Aljabar Max-Plus Pada Pemodelan Dan Penjadwalan Monorel dan Trem yang Terintegrasi di Kota Surabaya, Tugas Akhir Matematika ITS, 2013, Surabaya.

[2] Hasanah, U, dan Putrawangsa, S, Penggunaan Aljabar Maxplus Dalam Pembentukan Model Matematis Pada Sistem Penjadwalan Praktikum Laboratorium, Beta Jurnal Tadris Matematika 8 (1), 2015, 66-78.

[3] Ira, R.A., Eddi, B.K., dan Hariyani, S., Kinerja Dan Rute Pelayanan Angkutan Kota Di Kawasan Perkotaan Lumajang - Kabupaten Lumajang, Jurnal Tata Kota dan Daerah 2 (2), 2010, 9-17.

[4] Nurhayati, L, Sudarsana, I W, dan Lusiyanti, D, Pembuatan Skema Jalur Angkutan Kota Palu Berdasarkan Pencarian Lintasan Dengan Bobot Maksimum Menggunakan Algoritma Ant Colony System (ACS), Jurnal IImiah Matematika dan Terapan 12 (1), 2015, 44-52.

[5] Oktafianto, K, Implementasi Aljabar Max-Plus pada Pemodelan dan Penjadwalan Keberangkatan Bus Kota Damri Studi Kasus di Surabaya, Tugas Akhir Matematika ITS, 2013, Surabaya.

[6] Rakhmawati, N, Studi Penerapan Bus Sekolah di Jombang Menggunakan Aljabar Max-Plus, Modul Kuliah, 2014, Yogyakarta.

[7] Rianty, N, Transfortasi, http://id.wikipedia.org/wiki/Transfortasi, 2015, Diakses 19 februarii 2016.

[8] Subiono, Aljabar Maxplus dan Terapannya, Buku Ajar Kuliah Pasca Sarjana Matematika, ITS, 2012, Surabaya.

[9] Subiono, Aljabar Max-Plus dan Terapannya, Modul Kuliah, Jurusan Matematika FMIPA ITS, 2015, Surabaya. 